\title{
Vertrauen verspielt
}

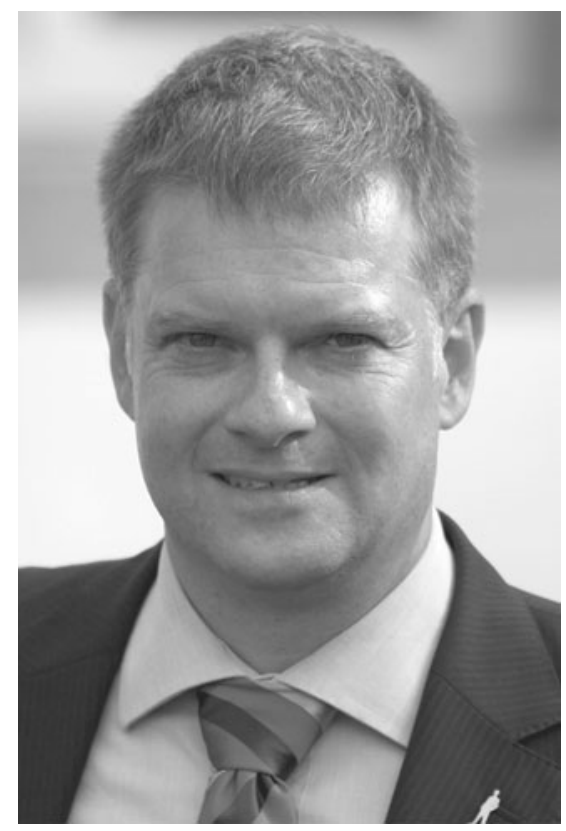

Das Konstrukt ist sehr elegant. Lässt ein Unternehmen personenbezogene Daten seiner Kunden oder Mitarbeiter durch einen Dritten verarbeiten - Lettershop, CRM-Anbieter, Rechenzentrum oder IT-Dienstleister - wird dies als Auftragsdatenverarbeitung geregelt: Die Verantwortung für den Schutz und die ausschließlich zweckbezogene Verarbeitung der personenbezogenen Daten verbleibt beim Unternehmen, der Auftragnehmer erhält konkrete vertragliche Weisungen, wie die Verarbeitung zu erfolgen hat. Der Auftraggeber überzeugt sich davon, dass diese auch umgesetzt werden - und der Gesetzgeber privilegiert diese Verarbeitung, indem er sie so behandelt, als ob sie im Unternehmen verbleiben würde. Seit der Konkretisierung des $\S 11$ BDSG im Jahr 2009 auf 10 Vertragsinhalte, die die Datenschutzaufsichtsbehörden schon lange forderten, werden ADV-Verträge in Unternehmen auch ernst genommen - zweifellos ein wichtiger Beitrag zur Steigerung des Datenschutzniveaus bei IT-Dienstleistern und zur Reduzierung des nach wie vor erheblichen Umsetzungsdefizits. So weit, so gut.

Kompliziert wird es, wenn das nichteuropäische Ausland ins Spiel kommt, denn dort entspricht das Schutzniveau meist nicht dem der EU - oder besser: dem in der EG-Datenschutzrichtlinie geforderten. Um auch bei der Verarbeitung personenbezogener Daten über nationale Grenzen hinweg die Grundidee der Auftrags datenverarbeitung zu bewahren, wurden Standardvertragsklauseln entworfen. Und mit der für internationale Datenverarbeitungen besonders wichtigen USA wurden bereits Ende des letzten Jahrtausends die „Safe Harbor Principles“ vereinbart. Am 26.07.2000 von der EU-Kommission in Kraft gesetzt postulieren sie bei US-Unternehmen, die dieser Selbstverpflichtung beitreten, ein ausreichendes Datenschutzniveau.

Doch die eleganteste Konstruktion hilft nichts, wenn sie mit der Wirklichkeit wenig zu tun hat. Schon im April 2010 meldeten die Datenschutz-Aufsichtsbehörden Zweifel an und verpflichteten deutsche Unternehmen, die die Verarbeitung personenbezogener Daten an amerikanische Unternehmen auslagern, Nachweise für die Einhaltung der Grundsätze einzufordern. Inzwischen ist die - nach deutschem Recht unzulässige und in den Standardvertragsklauseln ausgeschlossene - Datenweitergabe an Nachrichtendienste amtlich: Alle im Zusammenhang mit der Prism-Affäre genannten Unternehmen, von Apple über Facebook und Google bis Microsoft, werden auf der Save-Harbor-Liste des US-Handelsministeriums geführt. Zumindest hinsichtlich des Zugriffs von US-Nachrichtendiensten ist die Save-Harbor-Vereinbarung also nicht das Papier wert, auf dem sie gedruckt ist. Und ohne ein völkerrechtlich gemeinsames und bindendes Verständnis des Persönlichkeitsschutzes werden derartige Vereinbarungen wohl auch in Zukunft keine diesbezügliche Schutzwirkung entfalten.

Folgerichtig hat die Konferenz der Datenschutzbeauftragten des Bundes und der Länder am 24.07.2013 der EU-Kommission eine Aufkündigung des Abkommens empfohlen und mit der Aussetzung der Standardvertragsklauseln gedroht. So schmerzlich das insbesondere für internationale Unternehmen sein dürfte: Es ist sehr zu hoffen, dass die EU diesmal Rückgrat zeigt - und die Persönlichkeitsrechte nicht auf demselben Altar opfert, auf dem sie bereits Flugpassagierdaten und Bankdaten (SWIFT) dem Großen Bruder dargebracht hat.

\section{Dirk Fox}

